\title{
Pediatric Combat Trauma
}

\author{
Rachel M. Russo $^{1,2}$ • Lucas P. Neff ${ }^{1,2,3,4}$
}

Published online: 1 October 2016

(C) Springer International Publishing AG (outside the USA) 2016

\begin{abstract}
Purpose of review Military physicians have amassed tremendous experience treating children with combat-related injuries in Iraq and Afghanistan. This review will present several treatment principles adapted from adult trauma care that were applied to children in war and consider their selective application in civilian practice.

Recent findings Many standard practices of adult trauma care were applied to the management of war-injured children. Initial reports of tourniquet use, tranexamic acid administration, and balanced blood transfusion suggest a benefit to the pediatric population. Constraints of providing intensive care in an austere environment required a shift in management toward aggressive limb salvage over amputation, and early palliation for severe brain injury or extensive burns.
\end{abstract}

This article is part of the Topical Collection on The Military Perspective

Lucas P. Neff

lpneff@gmail.com

Rachel M. Russo

rmrusso@ucdavis.edu

1 Department of General Surgery, University of California Davis Medical Center, OP 512, 2315 Stockton Blvd, Sacramento, CA 95817, USA

2 Clinical Investigation Facility, David Grant USAF Medical Center, Travis Air Force Base, CA, USA

3 Department of General Surgery, David Grant USAF Medical Center, 101 Bodin Circle, Travis Air Force Base, CA 94535, USA

4 Department of Surgery, Uniformed Services University of the Health Sciences, Bethesda, MA, USA
Summary Despite the obstacles that may limit the direct translation of trauma care principals to civilian settings, these wartime experiences offer robust and excellent preliminary data that might inform future investigations in the field of pediatric trauma care.

Keywords Trauma $\cdot$ Resuscitation $\cdot$ Pediatric $\cdot$ Military medicine $\cdot$ Combat medicine

\section{Introduction}

Over the last 15 years of combat operations, US Military surgeons have developed a wealth of practical experience in treating combat-related injuries in Iraq and Afghanistan. A significant proportion of those treated are local national children impacted by nearby warfare (5-30\% depending on location) $[1 \bullet, 2-4]$. One unique aspect of this collective experience is that trauma care was provided largely by physicians trained primarily to care for adults, with limited prior experience caring for injured children. Because pediatric trauma care tends to lag behind advancements in adult trauma management, war acted as an accelerator of change along multiple fronts. Treatment strategies well established in adult trauma care were applied to the care of children. Military surgeons carefully described their experiences, providing an invaluable opportunity to evaluate the application of these principals in pediatric trauma care and to consider their selective application in civilian practice (Table 1).

This review will present several major concepts in the care of combat-injured patients that were evaluated first for the treatment of adults, and then applied to children in war. 
Table 1 Summary of lessons learned from the application of adult trauma resuscitation principals to the treatment of combat-injured pediatric patients during Operation Iraqi Freedom and operation enduring freedom

\begin{tabular}{|c|c|c|}
\hline Topic & Translatable combat experience & Areas for future research \\
\hline Tourniquets & $\begin{array}{l}\text { Commercially available tourniquets can be applied to both adults } \\
\text { and children. } \\
\text { Liberal pre-hospital tourniquet use to treat children with extremity } \\
\text { injury or hemodynamic instability with unknown injuries has } \\
\text { potential benefits and relatively few complications. }\end{array}$ & $\begin{array}{l}\text { Maximum duration of tourniquet use in pediatric patients } \\
\text { Decision support for reducing un-indicated tourniquet } \\
\text { application }\end{array}$ \\
\hline Vascular repair & $\begin{array}{l}\text { Vascular reconstruction with autologous vein is feasible for } \\
\text { pediatric patients. } \\
\text { Consider future limb and vessel growth when weighing options } \\
\text { for definitive repair. } \\
\text { High index of suspicion for compartment syndrome with liberal } \\
\text { fasciotomy may improve limb salvage rates. }\end{array}$ & $\begin{array}{l}\text { Therapies to reduce death from non-compressible torso } \\
\text { hemorrhage } \\
\text { Long-term outcomes of vascular reconstruction in } \\
\text { pediatric patients }\end{array}$ \\
\hline Blood transfusion & $\begin{array}{l}\text { Damage control resuscitation and balanced transfusion seem to } \\
\text { have benefits in the pediatric trauma population. } \\
\text { Evaluation of platelet transfusion in pediatric patients is limited. }\end{array}$ & $\begin{array}{l}\text { Prospective data on transfusion ratios best suited for } \\
\text { pediatric population }\end{array}$ \\
\hline TXA & $\begin{array}{l}\text { Early TXA administration may confer survival benefits in } \\
\text { severely injured children. }\end{array}$ & $\begin{array}{l}\text { Timing, dosing, and mode of TXA administration need } \\
\text { clarification. }\end{array}$ \\
\hline Severe head injury & $\begin{array}{l}\text { GCS is the most significant predictor of outcomes. } \\
\text { The threshold for palliative care depends on host-nation } \\
\text { resources and discussions with family. Palliation may be } \\
\text { pursued more frequently in the deployed environment. }\end{array}$ & $\begin{array}{l}\text { Resuscitation strategies that optimize outcomes in the } \\
\text { poly-trauma patient with hemorrhagic shock and brain } \\
\text { injury }\end{array}$ \\
\hline Burns & $\begin{array}{l}\text { Burn care is resource intense, particularly when burns are } \\
\text { extensive or associated with inhalational injury. } \\
\text { The threshold for palliative care depends on host-nation } \\
\text { resources and discussions with family. Palliation may be } \\
\text { pursued more frequently in the deployed environment. }\end{array}$ & $\begin{array}{l}\text { Resuscitation strategies to balance fluid requirements with } \\
\text { risk of inflammatory lung injury and volume overload }\end{array}$ \\
\hline Mangled extremity & $\begin{array}{l}\text { Severe extremity injury is associated with significant } \\
\text { psychological distress. Consider screening for post- } \\
\text { traumatic stress disorder. }\end{array}$ & $\begin{array}{l}\text { Long-term outcomes of aggressive limb salvage vs. } \\
\text { amputation for pediatric patients }\end{array}$ \\
\hline
\end{tabular}

TXA tranexamic acid, GCS Glasgow Coma Score

\section{Epidemiology}

Cumulatively, US military medical facilities have treated 7500 pediatric patients during the first 10 years alone, accounting for $11 \%$ of all in-patient bed days [1••]. At a single Air Force Hospital (332nd Expeditionary Medical Group Air Force Theater Hospital), the number of children treated for lifethreatening injuries was more than 23 per month, more than the required number of admissions for level I pediatric trauma centers in the USA [5]. Compared to the civilian sector, pediatric patients with war-related injuries tend to have more penetrating injury ( $64 \%$ blast or gunshot in military) and be more severely injured (as many as $50 \%$ of patients having ISS $>15$, Fig. 1) $[1 \bullet \cdot 6]$. The full spectrum of pediatric ages was represented, ranging from 2 days to 18 years old (median $=$ 9 years) [7]. The experience gained by treating patients with this significant burden of traumatic disease over 15 years of war is unmatched in peacetime conditions. However, the lessons learned from this experience can inform the medical response to incidents such as mass shootings and natural disasters that shift pediatric trauma from predominantly blunt, low severity injuries to those more reminiscent of wartime.

\section{Principles of Management}

\section{Tourniquets}

The high incidence of traumatic amputation from blast and penetrating injury to the extremities over the last decade of US military operations has created resurgence in the use of this very simple and effective maneuver to arrest hemorrhage. Numerous studies have clearly demonstrated that tourniquets have saved the lives of combat casualties with extremity hemorrhage [8]. However, little data is available on the use of tourniquets for injured children. One published review of the Department of Defense Trauma Registry (DoDTR) reported the experience of tourniquet use for 88 children [9*0]. They noted that the mechanics of applying tourniquets designed for adults to the smaller limbs of children were not problematic. This has clear implications for civilian pre-hospital providers who are often equipped with only one brand and size of tourniquet on their ambulances.

This experience also highlighted that a clear understanding of indications for tourniquet use is essential when placing them on children. In a chaotic combat environment, delivering "care under fire" may necessitate rapid treatment measures 


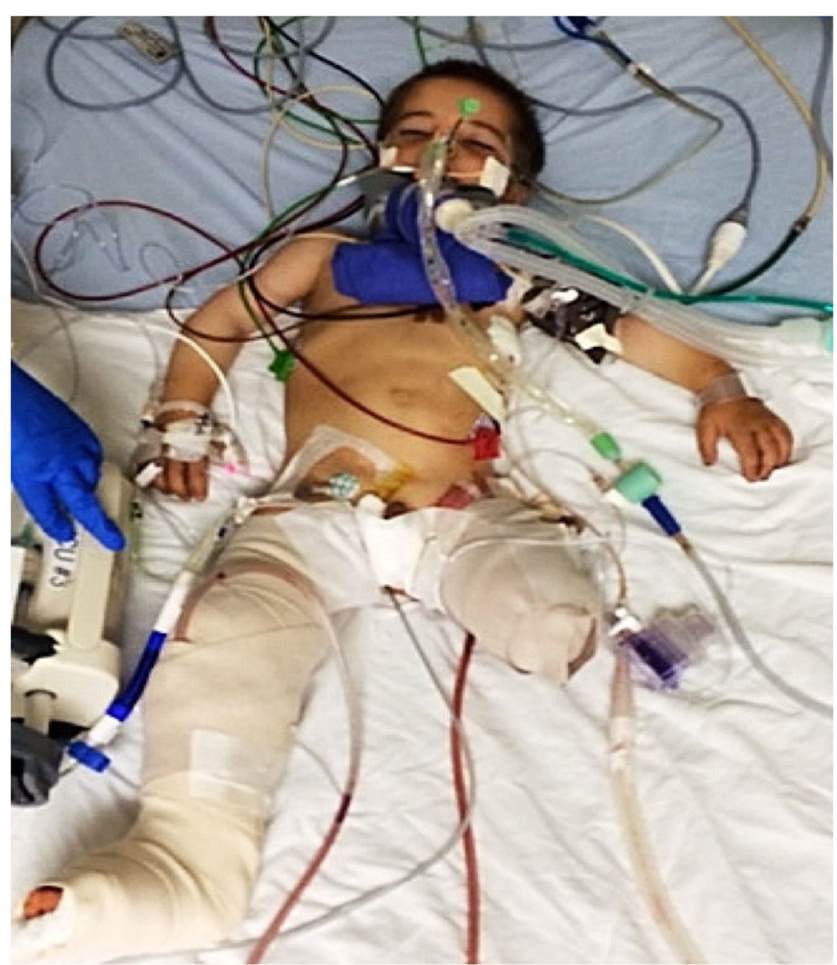

Fig. 1 Local national child injured by nearby warfare. This patient experienced severe traumatic brain injury and bilateral lower extremity injury with traumatic amputation of the left leg above the knee from an improvised explosive device. After several days of supportive care, operative debridement, and ventilator support, the patient was transferred to a local national facility

with inadequate patient exposure or full identification of injuries. Likewise, civilian pre-hospital providers may also be in situations where they are unable to fully evaluate the patient before leaving the scene. This is not often the case, but in the rare event of massive hemorrhage in a patient whose total blood volume is fairly small, providers should err on the side of overly aggressive tourniquet application. The rationale for having this low threshold is borne out of military experience in which $21(24 \%)$ of the patients presented to a military treatment facility with a tourniquet in place and no significant extremity injury on further inspection [9••]. The authors were careful to note that no complications from unindicted tourniquet use were reported. Therefore, liberal use of standard tourniquets should be advocated in situations where there is significant blood loss or traumatic amputation.

Current guidelines in adults recommend the restoration of distal extremity perfusion as soon as possible and absolutely within $6 \mathrm{~h}$ to avoid irreversible ischemia [10]. The generally accepted maximum duration of tourniquet use in children is approximately $2 \mathrm{~h}$ [11]. To date, there are no published reports of compartment syndrome in children as a result of tourniquets remaining in place for prolonged durations. However, duration of application should be given special attention by providers as recent adult experience has suggested an association of transient nerve paralysis, deep venous thrombosis, and need for subsequent amputations with prolonged tourniquet use [12]. A detailed history of the exact time of tourniquet application by pre-hospital providers is essential and every effort made to release the tourniquet as soon as safe and practical.

\section{Vascular Repair}

The management of wartime vascular injuries has led to significant advancements within the adult trauma population. Principles that have emerged from this experience include the endovascular management of trauma, an increased emphasis on early revascularization via temporary arterial shunting, and the early application of extremity fasciotomy to treat or avoid compartment syndrome. The result is a general acceptance of the management practices refined from combat casualty care [10].

The US military has collected one of the largest series of significant pediatric penetrating vascular injuries to date [13••]. The incidence of arterial injury in combat-injured children during Operation Iraqi Freedom exceeded $75 \%$ in some reports [14•]. As in adult casualties, the use of tourniquets, temporary vascular shunts, and liberal fasciotomy in combat-injured children led to significant limb-salvage rates (80\% amputation-free survival) [14•]. The overall survival rate reported at a single combat support hospital in Baghdad reached $96 \%$ (the only death occurred from ventilator malfunction in route to a local national hospital) [14•]. By way of comparison, a contemporary civilian series reported only a $1 \%$ incidence of vascular injury in children with an associated mortality rate of $16 \%$ [15]. While few conclusions can be made about this increased mortality in the civilian sector, few would argue that the high volume and adherence to well-defined vascular trauma management principles by military surgeons was beneficial.

The most common cause of death from pediatric vascular injury in the combat setting is truncal hemorrhage, likely secondary to the most common mechanism of injury being explosive blast and the difficulty with controlling truncal hemorrhage in the field [13••]. However, mortality rates in warinjured children with truncal vascular injury are ten times lower than their civilian counterparts [13••, 14•]. As with extremity vascular injuries, some have speculated that early adoption of damage control resuscitation strategies including balanced transfusion, goal-directed resuscitation, and limitation of crystalloid administration may contribute to this improved survival $[13 \cdot \bullet, 14 \bullet]$.

Arterial repair strategies from combat-injured children were similar to adults and were likely a function of the military surgical mindset and approach. The result is that more aggressive attempts at definitive vascular repair, such as autologous vein interposition grafting, were undertaken twice as often would otherwise occur in the civilian setting [13••, 16, 17]. 
In civilian trauma centers, observation, primary repair, and ligation tend to predominate over vascular reconstruction in the approach to pediatric vascular injury $[13 \bullet \bullet, 16,17]$. This military series also reported a $17 \%$ incidence of temporary vascular shunt placement for lower extremity arterial injury with no complications observed [13••]. However, an increased propensity toward vasospasm led to frequent intra-arterial administration of vasodilators such as papaverine and nitroglycerin $[13 \bullet \bullet]$. Heparin was use cautiously due to the risk of systemic effects in smaller patients [13••]. Additional recommendations that differ from the treatment of adults included a preference for duplex ultrasonography instead of completion angiography for evaluating the repair, due to the risk of iatrogenic injury to small caliber vessels [18]. Treatment recommendations for venous injury were similar to adults; however, ligation of large venous structures (iliac vein, common femoral vein, and popliteal vein) was discouraged due to the theoretical risk of deep venous thrombosis, although there is no supporting data $[18,19]$.

Following vascular repair, as in adults, careful consideration for the risk of extremity compartment syndrome is paramount. In the multiply injured child that is intubated and sedated, it is often difficult to follow the standard clinical indicators of increasing compartment pressures (pulselessness, pain, pallor, parathesias, paralysis, poikilothermia - the 6 "P's"). Moreover, pediatric appropriate indicators such as agitation, anxiety, and increased analgesic requirements (the 3 "A's") may be more useful [20]. Fasciotomy with release of all fascial compartments in the affected extremity is advised to avoid compartment syndrome and its sequellae [20]. This maneuver can be achieved via the standard volar and dorsal incisions of the forearm and the medial and anteriolateral incisions of the lower leg. Often, this diagnosis occurs in children with fractures of the extremities and associated vascular injury/thrombosis or hemorrhage into the fascial compartments [21]. To date, the largest military experience reported that nearly half of patients with lower extremity revascularization required fasciotomy and there were no reported complications [13・•]. Finally, the last 15 years of military medicine has proven the utility of vacuum-assisted closure devices for the management of the fasciotomy wounds and their eventual closure [13••]. While specifics regarding the overall utilization of negative pressure dressings is limited, certainly they are considered standard practice for preparing the wound bed for eventual skin grafting or primary closure of the fascial compartment.

One notable gap in the military experience with vascular trauma is long-term follow-up, especially for extremity arterial repairs or ligations. Civilian experience in several small series would suggest that return to normal activities and continued growth of the affected limb would be expected in the vast majority [22]. However, the inability to systematically capture the outcomes of children that were eventually discharged to host national medical facilities or home prevents a broader understanding of the deployed surgeon's more aggressive operative approach to blood vessel reconstruction. Nonetheless, when arterial reconstruction is required, interrupted suture is recommended over continuous suturing at the anastomosis out of concern that running suture will lead to anastomotic narrowing as the patient grows and conduit vessels enlarge [14•]. Similarly, avoidance of prosthetic conduit is recommended in growing children due to the concern for eventual size mismatch.

\section{Blood Transfusion}

Arguably the most important advancement in trauma care from the military experience over the last 15 years has been the advent of "balanced" blood product transfusion and "Damage Control Resuscitation" using equivalent amounts of packed red blood cells, fresh frozen plasma, platelets, and cryoprecipitate. The degree of blood loss resulting from severe combat injuries frequently required massive transfusion of large volumes of blood products. Numerous military accounts of experience in Iraq and Afghanistan have indicated that patients receiving equal or near equal ratios of packed red blood cells to fresh frozen plasma and platelets had increased survival [23-26]. Along with these retrospective studies, several prospective observational studies have sought to further refine current trauma transfusion practices [27]. The widespread and enthusiastic adoption of "balance resuscitation" practices in the adult population has translated into changes in pediatric care as well [28-33]. This shift in balanced resuscitation for injured children, however, has not been thoroughly studied due to the relative infrequency of massive transfusions in children. In addition to the relative paucity of data, existing retrospective reports describe a heterogeneous patients population, including those with confounding traumatic brain injury or incomplete data from combat trauma [3435••]. Taken togeth$\mathrm{er}$, these issues may obscure the effects of transfusion practices that mimic the adult guidelines. Moreover, the robust experience with combat-injured children may not translate well to the civilian trauma population, as explosive and penetrating mechanisms of injury tend are relatively rare outside the military cohort [36].

As in the adult trauma population, what constitutes a "massive transfusion" for children is quite debatable. To date there has not been a consensus definition of massive transfusion in the pediatric population. Yet, developing an accurate definition for large volume blood resuscitations as a predictor of mortality is an important method of identifying a population at risk for death that might benefit from an intervention. Such a definition would then provide a basis for comparison to optimize techniques and save lives. The most commonly held definition of massive transfusion for children is the adminis-

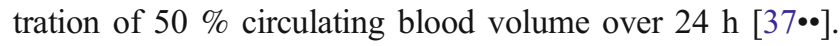


However, like the definition of massive transfusion for adults, this definition is arbitrary and has never been validated, leading some to question the very utility of such a measure $[28,29,37 \bullet \bullet, 38,39]$. The DoDTR has one of the largest collections of children receiving large volumes of blood transfusions for traumatic injury. A recently published study by Neff et al. found that combat-injured children requiring transfusion of more than $40 \mathrm{~mL} / \mathrm{kg}$ of blood products (equivalent to approximately half the circulating blood volume of most children) within the first $24 \mathrm{~h}$ after injury have higher mortality, indicating this threshold as a potential definition of massive transfusion [27]. Large, prospective observation studies of injured children requiring massive transfusion are currently ongoing and will provide greater insight on optimization of blood product administration. Until further information does come to light, the presumed benefits of balanced blood product administration have led many US pediatric trauma centers to adopt modified versions of adult massive transfusion protocols $[30,32,33]$.

\section{Tranexamic Acid (TXA)}

Timely administration of tranexamic acid (TXA) is associated with reduced morbidity and mortality in hemorrhaging adult trauma patients [40-42]. The international CRASH-2 trial was followed by a critical appraisal of TXA utility in the combat trauma setting for adults and was found to be even more beneficial than in civilian trauma. Despite this benefit, there is a paucity of data on the use of TXA for pediatric trauma patients [40].

In 2014, Eckert et al. published the largest retrospective review to date on the use and efficacy of TXA in pediatric combat casualties [43••]. TXA administration was independently associated with decreased mortality. Indications for TXA use in pediatric patients tend to be similar to indications in adults, but firm criteria for the timing, dosing, and route of administration are not yet elucidated [43••]. Most commonly, TXA was used to treat patients with severe abdominal or extremity injury (AIS $>3$ ) and signs of severe hemorrhage (hypotension, acidosis, coagulopathy, base deficit $>5$ ) [43••]. In this series, there were no differences in thromboembolic or cardiac events in the cohort that received TXA and similarly injured patients that did not. In addition to conferring a survival advantage, TXA use was also correlated with decreased ventilator dependence and significantly improved neurologic outcomes at discharge [43••].

While this experience is consistent with safety data from the use of TXA in pediatric patients undergoing major elective surgery, there is no consistency in dosing between published studies $[44,45]$. As the first study to evaluate the effect of TXA on mortality in severely injured pediatric patients, its administration was identical to adult dosing-single fixed bolus dose of $1 \mathrm{~g}$ of TXA administered within $3 \mathrm{~h}$ of injury with an additional $1 \mathrm{~g}$ infused over the subsequent $8 \mathrm{~h}$ for all children who received TXA regardless of injury severity, age, or weight $[43 \bullet \bullet]$.

In conclusion, the body of literature on the use of TXA in pediatric trauma patients is limited and based on a small number of retrospective studies examining a heterogeneous patient population. Furthermore, there is still a need to establish appropriate dosing recommendations for children. These issues notwithstanding, the potential benefits of timely TXA administration in severely injured pediatric trauma patients lend its use to be considered.

\section{Severe Head Injury}

Traumatic brain injury is a significant cause of morbidity and mortality for adult and pediatric trauma patients in war and peacetime. Traumatic brain injury is the most common cause of death for war-injured children $[1 \bullet \bullet, 2,36,46]$. In contrast with the civilian population, the most common mechanism of wartime brain injury is penetrating (61\%), with blast injury $(89 \%)$ and gunshot injury (16\%) being the most common means $[47,48 \bullet$. Similar to pediatric civilian trauma patients with blunt head injury, war-injured children with low Glasgow Coma Scores (GCS) on admission were more likely to die than those with GCS $>9$ [47, 48 $]$. In a study by Klimo et al., each one-point increase in GCS resulted in a $32 \%$ increased odds of survival [48•]. Other predictors of poor outcome were abnormal or non-reactive pupils and hypotension [47].

More than half of the patients required craniotomy, craniectomy, or intracranial pressure monitoring [47, 48•, 49]. Despite this seemingly high volume of invasive interventions, concerns for infection in the austere environment limited ventricular catheter use compared to usual civilian practice [49]. To reduce the risk of infection, all patients with invasive interventions or penetrating head injury received $24 \mathrm{~h}$ of treatment with a third-generation cephalosporin [49]. When high intracranial pressure was detected, hypertonic saline and drainage of cerebrospinal fluid were the mainstays of non-operative management [49]. When surgery was required, principals of operative management included aggressive removal of all scalp hair, aggressive subtemporal decompression, minimal surface debridement (no debridement of the tract for penetrating missile injury), duraplasty with onlay dural substitute if needed, and subcutaneous abdominal bone flap preservation for late reconstruction [47]. A high risk for venous thrombosis in postpubescent patients led to aggressive use of fractionated heparin as early as $12 \mathrm{~h}$ following surgery [49]. Because there was little local support for the long-term management of severely brain injured children, palliative care was pursued more liberally for those patients with low GCS compared to care delivered in the US civilian population [47]. 


\section{Burn Injury}

The last 15 years of combat operations have resulted in tremendous burden of combat injury with associated burn injury for US service members. This high incidence of severe burn injury has resulted in countless insights into the initial resuscitation, surgical management, and critical care for adult burn victims.

Depending on the phase of war, the relative proportion of pediatric patients presenting with burn injury ranged from 8 to $56 \%$, frequently combined with multiple other injuries as a result of explosion or blast [50]. Mortality was highest when burn injury was combined with head injury or inhalational injury [51]. Patients with this combination of injury required resource-intensive management. Local national facilities frequently lacked critical care or ventilator support, rehabilitation, reconstruction, or long-term care resources [51]. As a result, the majority of care provided for patients with significant burn injury was completed at military treatment facilities. Additionally, palliation was pursued more frequently in this patient population than would ordinarily be the case in a wellresourced trauma center in the USA [51]. Frequent lack of pediatric-specific equipment, especially early on during the war, also contributed to the high mortality seen in young children with burn injury; children under 6 years old were nearly three times more likely to die than similarly injured older children or adults [52]. Perhaps in part due to poor baseline health and malnutrition present in children living in war-torn countries and in part due to the constraints of delivering pediatric burn care in the deployed combat environment, mortality in children with $>30 \%$ total body surface area burns was three times higher in war-injured patients with isolated burn injury than is reported in the US civilian population [51]. Because of baseline health disparities, resource limitations, and the medical rules of engagement, many of the management considerations that guide therapy during combat operations differ greatly from care delivered in US burn centers. Moreover, the lack of ancillary services like physical therapy and longterm follow-up prevent a full understanding of outcomes for burned children in combat environments.

\section{Mangled Extremity}

The Military Extremity Trauma Amputation/Limb Salvage (METALS) study was a large retrospective study comparing long-term morbidity and quality of life outcomes in patients with mangled lower extremities treated either with limb salvage or amputation [53]. This study changed practice in combat casualty care after demonstrating that service members that underwent amputation had better functional outcomes than those that underwent limb salvage. The success of early amputation in this population may be multifactorial [54]. This young, otherwise healthy, highly motivated cohort of patients has access to excellent follow-up care including dedicated rehabilitation services and advanced prosthetics. When caring for local national children in Iraq and Afghanistan, these rehabilitative therapies and prosthetic options were often not available. As such, extreme effort was focused on limb salvage whenever possible even in situations in which service members with the same injuries would have undergone amputation [55]. The experience of caring for injured children in these resource-limited environments is not analogous to the US civilian pediatric trauma practice. As such, there is limited literature to aid in the decision between early amputation verses limb salvage for the child with a mangled extremity. Yet, providers can draw on the experience of the METALS study to inform pediatric management decisions for children in well-resourced clinical contexts. One other important finding of the METALS study was a high degree of PTSD in patients that had severe extremity injury [53]. While this study did not evaluate children, the psychological impact of these severe injuries on children should be considered.

\section{Humanitarian and Non-trauma Care}

While much of the pediatric care delivered by military medical forces in Iraq and Afghanistan was for the treatment of combat-related injuries, hundreds of elective pediatric operations have been performed as a part of the ongoing humanitarian mission $[56,57 \bullet, 58 \bullet \bullet$. Performing elective pediatric operations in the deployed setting requires thoughtful consideration of resource utilization to ensure capabilities remain to support the care of combat-injured soldiers in the event of a sudden mass casualty event. Irrespective of the clinical capabilities of the combat support hospital, surgeons must consider the environment and health care infrastructure of the host nation. The availability of ancillary services, adjunctive therapies, and follow-up care heavily influences the decision to operate. Furthermore, the impact of cultural practices and social norms may have an impact on quality of life, and therefore may influence the operation performed. Sometimes a simpler but less optimal plan may be preferable to the "gold standard." However, an appropriately selected elective operation presents a unique opportunity to transform the life of a child and their family.

As with civilian humanitarian surgical missions, the US Military places an emphasis on procedures that are low risk, can be performed quickly, require limited follow-up, and do not undermine the host nation medical system. However, there is very little information available in the literature on the scope and outcomes of humanitarian pediatric surgical care performed during recent conflicts. A recently published retrospective review detailed the military experience providing humanitarian pediatric surgery during a 2 -year period at a single combat support hospital (Craig Joint Theater Hospital in Bagram, Afghanistan). The surgical care offered was immense 
and diverse; 311 elective operations were performed on 239 children, encompassing 30 types of surgical procedures performed by six different surgical specialties. Otolaryngology and urology procedures accounted for the majority of operations [58・•], in contrast to other published reports of the military humanitarian experience in which general surgical and orthopedic procedures tended to predominate [57•]. This report highlights the success of providing single-stage outpatient operations with few complications and limited need for follow-up. However, it also emphasizes the high rate of complications following neurosurgical interventions (neurosurgical operations accounted for nearly three quarters of all complications requiring reoperation). This finding underscores the need for long-term follow-up and enhanced infection control measures in the austere environment following neurosurgical intervention. Similar to civilian humanitarian surgery, military surgeons struggled with their inability to address the social, economic, and environmental factors that led to the need for surgery. For example, operations for nephrolithiasis were commonly required to decrease pain, infections, and the risk of renal failure; however, without addressing the underlying cause of nephrolithiasis, surgical intervention was only a temporary solution $[58 \bullet \bullet, 59]$. Finally, like the pediatric trauma population, male patients outnumbered female patients $3: 1$, which may be indicative of cultural gender values affecting patient presentation.

\section{Conclusions}

Fifteen years of ongoing combat in the Middle East and Southeast Asia has led to robust military experience treating severe traumatic injuries in adults and children. Many of the practices that are now common standards in adult trauma care were also applied in war-injured children. Initial reports of some of these principals, including tourniquet use, TXA administration, and balanced blood transfusion suggest a benefit to the pediatric population. Despite the obstacles that may limit the direct translation of trauma care principals to civilian settings, these wartime experiences offer robust and excellent preliminary data that can inform future studies of civilian pediatric trauma care.

\section{Compliance with Ethical Standards}

Conflict of Interest Drs. Russo and Neff declare no conflicts of interest relevant to this manuscript.

Human and Animal Rights and Informed Consent This article does not contain any studies with human or animal subjects performed by any of the authors.

Disclaimers The views expressed in this material are those of the authors and do not reflect the official policy or position of the US
Government, the Department of Defense, the Department of the Air Force, or the University of California Davis.

Funding There was no funding from the National Institutes of Health (NIH), Wellcome Trust, or the Howard Hughes Medical Institute (HHMI) for this work.

\section{References}

Papers of particular interest, published recently, have been highlighted as:

- Of importance

•. Of major importance

1.• Borgman M, Matos RI, Blackbourne LH, Spinella PC. Ten years of military pediatric care in Afghanistan and Iraq. J Trauma Acute Care Surg. 2012;73(6 Suppl 5):S509-13. This retrospective review compares the epidemiology and outcomes of pediatric and adult admissions to US military medical treatment facilities in Iraq and Afghanistan from 2001-2011.

2. Edwards MJ, Lustik M, Eichelberger MR, et al. Blast injury in children: an analysis from Afghanistan and Iraq, 2002-2010. J Trauma Acute Care Surg. 2012;73(5):1278-83.

3. Idenburg FJ, van Dongen TT, Tan EC, et al. Pediatric surgical care in a Dutch military hospital in Afghanistan. World J Surg. 2015;39(10):2413-21.

4. Ramasamy A, Hinsley DE, Edwards DS, et al. Skill sets and competencies for the modern military surgeon: lessons from UK military operations in Southern Afghanistan. Injury. 2010;41(5):453-9.

5. Cannon JW, Smith DL. The pediatric care crisis in Iraq. Crit Care Med. 2009;37(7):2322.

6. Inwald DP, Arul GS, Montgomery M, et al. Management of children in the deployed intensive care unit at Camp Bastion, Afghanistan. J R Army Med Corps. 2014;160(3):236-40.

7. Borgman MA, Maegele M, Wade CE, et al. Pediatric trauma BIG score: predicting mortality in children after military and civilian trauma. Pediatrics. 2011;127(4):e892-7.

8. Beekley AC, Sebesta JA, Blackbourne LH, et al. Prehospital tourniquet use in Operation Iraqi Freedom: effect on hemorrhage control and outcomes. J Trauma. 2008;64(2 Suppl):S28-37. discussion S.

9.• Kragh Jr JF, Cooper A, Aden JK, et al. Survey of trauma registry data on tourniquet use in pediatric war casualties. Pediatr Emerg Care. 2012;28(12):1361-5. This retrospective review of the Joint Trauma System's Joint Theater Trauma Registry evaluates combat-injured pediatric patients that were treated with extremity tourniquets between 2003 and 2009.

10. USAISR. Clinical practice guidelines [Available from: http://usaisr. amedd.army.mil/clinical practice guidelines.html]

11. Klenerman L. The tourniquet manual. London: Springer; 2003.

12. Kragh Jr JF, Walters TJ, Baer DG, et al. Practical use of emergency tourniquets to stop bleeding in major limb trauma. J Trauma. 2008;64(2 Suppl):S38-49. discussion S-50.

13.• Villamaria CY, Morrison JJ, Fitzpatrick CM, et al. Wartime vascular injuries in the pediatric population of Iraq and Afghanistan: 20022011. J Pediatr Surg. 2014;49(3):428-32. This retrospective review of the Department of Defense Trauma Registry details the epidemiology of vascular injury, interventions, and outcomes of combat related vascular injuries in Iraqi and Afghani children from 2001-2011. 
14. Dua A, Via KC, Kreishman P, et al. Early management of pediatric vascular injuries through humanitarian surgical care during U.S. military operations. J Vasc Surg. 2013;58(3):695-700. This article evaluates the efficacy of damage control resuscitation principals to achieve limb salvage in pediatric patients with severe extremity vascular injury over a 2-year period in a combat hospital in Baghdad, Iraq.

15. Allison ND, Anderson CM, Shah SK, et al. Outcomes of truncal vascular injuries in children. J Pediatr Surg. 2009;44(10):1958-64.

16. Corneille MG, Gallup TM, Villa C, et al. Pediatric vascular injuries: acute management and early outcomes. J Trauma. 2011;70(4):8238.

17. Klinkner DB, Arca MJ, Lewis BD, et al. Pediatric vascular injuries: patterns of injury, morbidity, and mortality. J Pediatr Surg. 2007:42(1):178-82. discussion 82-3.

18. de Virgilio C, Mercado PD, Arnell T, et al. Noniatrogenic pediatric vascular trauma: a ten-year experience at a level I trauma center. Am Surg. 1997;63(9):781-4.

19. Quan RW, Adams ED, Cox MW, et al. The management of trauma venous injury: civilian and wartime experiences. Perspect Vasc Surg Endovasc Ther. 2006;18(2):149-56.

20. Hosseinzadeh P, Hayes CB. Compartment syndrome in children. Orthopedic Clinics.

21. Bae DS, Kadiyala RK, Waters PM. Acute compartment syndrome in children: contemporary diagnosis, treatment, and outcome. J Pediatr Orthop. 2001;21(5):680-8.

22. Harris LM, Hordines J. Major vascular injuries in the pediatric population. Ann Vasc Surg. 2003;17(3):266-9.

23. Sihler KC, Napolitano LM. Massive transfusion: new insights. Chest. 2009;136(6):1654-67.

24. Borgman MA, Spinella PC, Perkins JG, et al. The ratio of blood products transfused affects mortality in patients receiving massive transfusions at a combat support hospital. J Trauma. 2007;63(4): 805-13.

25. Hendrickson JE, Shaz BH, Pereira G, et al. Coagulopathy is prevalent and associated with adverse outcomes in transfused pediatric trauma patients. J Pediatr. 2012;160(2):204-9.e3.

26. Schuster KM, Davis KA, Lui FY, et al. The status of massive transfusion protocols in United States trauma centers: massive transfusion or massive confusion? Transfusion. 2010;50(7):1545-51.

27. Holcomb JB, del Junco DJ, Fox EE, et al. The prospective, observational, multicenter, major trauma transfusion (PROMMTT) study: comparative effectiveness of a time-varying treatment with competing risks. JAMA Surg. 2013;148(2):127-36.

28. Paterson NA. Validation of a theoretically derived model for the management of massive blood loss in pediatric patients - a case report. Paediatr Anaesth. 2009;19(5):535-40.

29. Diab YA, Wong EC, Luban NL. Massive transfusion in children and neonates. Br J Haematol. 2013;161(1):15-26.

30. Chidester SJ, Williams N, Wang W, Groner JI. A pediatric massive transfusion protocol. J Trauma Acute Care Surg. 2012;73(5):12737.

31. Hendrickson JE, Shaz BH, Pereira G, et al. Implementation of a pediatric trauma massive transfusion protocol: one institution's experience. Transfusion. 2012;52(6):1228-36.

32. Pickett PM, Tripi PA. Massive transfusion protocol in pediatric trauma. Int Anesthesiol Clin. 2011;49(2):62-7.

33. Dressler AM, Finck CM, Carroll CL, et al. Use of a massive transfusion protocol with hemostatic resuscitation for severe intraoperative bleeding in a child. J Pediatr Surg. 2010;45(7):1530-3.

34. Nosanov L, Inaba $\mathrm{K}$, Okoye $\mathrm{O}$, et al. The impact of blood product ratios in massively transfused pediatric trauma patients. Am J Surg. 2013;206(5):655-60.

35.• Edwards MJ, Lustik MB, Clark ME, et al. The effects of balanced blood component resuscitation and crystalloid administration in pediatric trauma patients requiring transfusion in Afghanistan and Iraq
2002 to 2012. J Trauma Acute Care Surg. 2015;78(2):330-5. This retrospective review of the Department of Defence Trauma Registry evaluates pediatric patients requiring transfusion for combat-related injury at deployed US military hospitals between 2002 and 2012.

36. Burd RS, Jang TS, Nair SS. Evaluation of the relationship between mechanism of injury and outcome in pediatric trauma. J Trauma. 2007;62(4):1004-14.

37.• Neff LP, Cannon JW, Morrison JJ, et al. Clearly defining pediatric massive transfusion: cutting through the fog and friction with combat data. J Trauma Acute Care Surg. 2015; 78(1):22-8; discussion 8 9. This retrospective review of the Department of Defense Trauma Registry defined a transfusion threshold that reliably identifies critically injured children at high risk for early and inhospital death.

38. Stanworth SJ, Morris TP, Gaarder C, et al. Reappraising the concept of massive transfusion in trauma. Crit Care. 2010;14(6):R239.

39. Barcelona SL, Thompson AA, Cote CJ. Intraoperative pediatric blood transfusion therapy: a review of common issues. Part I: hematologic and physiologic differences from adults; metabolic and infectious risks. Paediatr Anaesth. 2005;15(9):716-26.

40. Shakur H, Roberts I, Bautista R, et al. Effects of tranexamic acid on death, vascular occlusive events, and blood transfusion in trauma patients with significant haemorrhage (CRASH-2): a randomised, placebo-controlled trial. Lancet. 2010;376(9734):23-32.

41. Morrison JJ, Ross JD, Dubose JJ, et al. Association of cryoprecipitate and tranexamic acid with improved survival following wartime injury: findings from the MATTERs II Study. JAMA Surg. 2013;148(3): 218-25.

42. Morrison JJ, Dubose JJ, Rasmussen TE, Midwinter MJ. Military Application of Tranexamic Acid in Trauma Emergency Resuscitation (MATTERs) Study. Arch Surg. 2012;147(2):113-9.

43.• Eckert MJ, Wertin TM, Tyner SD, Nelson DW, Izenberg S, Martin MJ. Tranexamic acid administration to pediatric trauma patients in a combat setting: the pediatric trauma and tranexamic acid study (PED-TRAX). J Trauma Acute Care Surg. 2014;77(6):852-8; discussion 8. A four year experience from Camp Bastion, Afghanistan, this is the largest retrospective review pediatric TXA administration during wartime.

44. Tzortzopoulou A, Cepeda MS, Schumann R, Carr DB. Antifibrinolytic agents for reducing blood loss in scoliosis surgery in children. Cochrane Database Syst Rev. 2008. (3):Cd006883.

45. Schouten ES, van de Pol AC, Schouten AN, et al. The effect of aprotinin, tranexamic acid, and aminocaproic acid on blood loss and use of blood products in major pediatric surgery: a meta-analysis. Pediatr Crit Care Med: J Soc Crit Care Med World Fed Pedia Int Crit Care Soc. 2009;10(2):182-90.

46. Edwards MJ, Lustik M, Carlson T, et al. Surgical interventions for pediatric blast injury: an analysis from Afghanistan and Iraq 2002 to 2010. J Trauma Acute Care Surg. 2014;76(3):854-8.

47. Wani AA, Ramzan AU, Malik NK, et al. Missile injury to the pediatric brain in conflict zones. J Neurosurg Pediatr. 2011;7(3): 276-81.

48. Klimo P, Jr., Ragel BT, Jones GM, McCafferty R. Severe pediatric head injury during the Iraq and Afghanistan conflicts. Neurosurgery. 2015; 77(1):1-7; discussion. This prospective analysis describes the epidemiology, treatment, and outcome of pediatric patients with severe head injury treated in Afghanistan from 2007-2009.

49. Martin JE, Teff RJ, Spinella PC. Care of pediatric neurosurgical patients in Iraq in 2007: clinical and ethical experience of a field hospital. J Neurosurg Pediatr. 2010;6(3):250-6.

50. McGuigan R, Spinella PC, Beekley A, et al. Pediatric trauma: experience of a combat support hospital in Iraq. J Pediatr Surg. 2007;42(1):207-10. 
51. Borgman MA, Matos RI, Spinella PC. Isolated pediatric burn injury in Iraq and Afghanistan. Pediatr Crit Care Med: J Soc Crit Care Med World Fed Pediatr Int Crit Care Soc. 2015;16(2):e23-7.

52. Spinella PC, Borgman MA, Azarow KS. Pediatric trauma in an austere combat environment. Crit Care Med. 2008;36(7 Suppl): S293-6.

53. Doukas WC, Hayda RA, Frisch HM, et al. The Military Extremity Trauma Amputation/Limb Salvage (METALS) study: outcomes of amputation versus limb salvage following major lower-extremity trauma. J Bone Joint Surg Am. 2013;95(2):138-45.

54. Rispoli DM, Mackenzie EJ. Orthopaedic outcomes: combat and civilian trauma care. J Am Acad Orthop Surg. 2012;20 Suppl 1: S84-7.

55. Peck MA, Clouse WD, Cox MW, et al. The complete management of extremity vascular injury in a local population: a wartime report from the 332nd Expeditionary Medical Group/Air Force Theater Hospital, Balad Air Base, Iraq. J Vasc Surg. 2007;45(6):1197204. discussion 204-5.
56. Fuenfer MM, Spinella PC, Naclerio AL, Creamer KM. The U.S. military wartime pediatric trauma mission: how surgeons and pediatricians are adapting the system to address the need. Mil Med. 2009;174(9):887-91.

57. Burnett MW, Spinella PC, Azarow KS, Callahan CW. Pediatric care as part of the US Army medical mission in the global war on terrorism in Afghanistan and Iraq, December 2001 to December 2004. Pediatrics. 2008;121(2):261-5. This article describe the epidemiology and workload associated with pediatric admissions to 12 US Army military hospitals deployed to Iraq and Afghanistan.

58.• Neff LP, Cannon JW, Charnock KM, Farmer DL, Borgman MA, Ricca RL. Elective pediatric surgical care in a forward deployed setting: what is feasible vs. what is reasonable. J Pediatr Surg. 2016;51(3):409-15. This article is the first review to include a comprehensive assessment of surgical procedures conducted as well as their follow up and outcomes for humanitarian pediatric surgery delivered by the U.S. military.

59. Brisson P, Woll M, Parker D, Durbin R. Bladder stones in Afghan children. Mil Med. 2012;177(11):1403-5. 